\title{
O INTERROGATÓRIO POLICIAL À LUZ DE FENÔMENOS DISCURSIVOS INTRÍNSECOS À ARGUMENTAÇÃO
}

\section{THE POLICE INTERROGATION IN THE LIGHT OF DISCURSIVE PHENOMENA INTRINSIC TO ARGUMENTATION}

\author{
Paola Gabriela Konrad ${ }^{1}$ \\ Maria Eduarda Giering ${ }^{2}$
}

\begin{abstract}
RESUMO
Este estudo, amparado pela concepção de ethos proposta por Amossy (2005) e pelos clássicos tipos de argumentos apresentados por Fiorin (2015), propõe-se a analisar fragmentos de fala pertencentes ao gênero discursivo interrogatório policial de modo a investigar (1) se o ethos prévio (AMOSSY, 2005) ou pré-discursivo (MAINGUENEAU, 2008) dos participantes do interrogatório policial se confirma no ethos discursivo dos enunciadores; e (2) os tipos de argumentos (FIORIN, 2015) utilizados pelos enunciadores do interrogatório policial. O corpus deste estudo advém de gravações em áudio e vídeo de três interrogatórios policiais de uma Delegacia de Polícia Civil do Estado do Rio Grande do Sul, Brasil. Quanto ao primeiro propósito deste estudo, no que tange aos policiais, seu ethos prévio se confirma discursivamente em todos os fragmentos de fala analisados. Em relação aos interrogados, a sua imagem prévia é reelaborada ao longo do discurso. Concernente ao segundo propósito deste estudo, uma série de tipo de argumentos são utilizados pelos enunciadores nos interrogatórios policiais, a saber: argumento de comparação, argumentum ad hominem, argumentum ad verecundiam, argumentum ad misericordiam e argumentum ad baculum. Por fim, a análise revela que os tipos de argumentos utilizados pelos policiais e pelos interrogados nas interações operam como recurso para a construção do ethos dos enunciadores.
\end{abstract}

PALAVRAS-CHAVE: Argumentação; Ethos; Tipos de Argumentos; Interrogatório Policial.

\begin{abstract}
This study, supported by the conception of ethos proposed by Amossy (2005) and by the classical types of arguments presented by Fiorin (2015), proposes to analyze speech fragments belonging to the police interrogation discursive genre in order to investigate (1) if the prior (AMOSSY, 2005) or pre-discursive (MAINGUENEAU, 2008) ethos of police interrogation participants is confirmed in the discursive ethos of the enunciators; and (2) the types of arguments (FIORIN, 2015) utilized by the enunciators of the police interrogation. The corpus of this study is composed of audio and video recordings of three police interrogations from a Civilian Police station in Rio Grande do Sul State, Brazil. Regarding the first purpose of this study, considering the police officers, their prior ethos is discursively confirmed in all analyzed speech fragments. In relation to the interrogated individuals, their prior image is reworked throughout the discourse. Concerning the second purpose of this study, a series of types of arguments are utilized by the enunciators in the police interrogations, namely: comparison argument, argumentum ad hominem, argumentum ad verecundiam, argumentum ad misericordiam e argumentum ad baculum. Finally, the analysis shows
\end{abstract}

\footnotetext{
${ }^{1}$ Mestra e Doutoranda em Linguística Aplicada pela Universidade do Vale do Rio dos Sinos (UNISINOS). Contato: paolagkonrad@gmail.com.

2 Doutora em Linguística e Letras pela Pontifícia Universidade Católica do Rio Grande do Sul (PUCRS) e professora titular no Programa de Pós-Graduação em Linguística Aplicada da Universidade do Vale do Rio dos Sinos (UNISINOS). Contato: eduardajg@gmail.com.
} 
that the types of arguments utilized by the police officers and by the interrogated individuals in the interactions function as a resource for the construction of the ethos of the enunciators.

KEYWORDS: Argumentation; Ethos; Types of Arguments; Police Interrogation.

\section{INTRODUÇÃO}

Todo e qualquer discurso é permeado por fenômenos intrínsecos à argumentação. Fiorin (2015, p. 9) explica que essa dimensão argumentativa dos discursos decorre de duas razões principais: "[...] de um lado, porque o modo de funcionamento real do discurso é o dialogismo; de outro, porque sempre o enunciador pretende que suas posições sejam acolhidas, que ele mesmo seja aceito, que o enunciatário faça dele uma boa imagem".

Ora, se todo e qualquer discurso possui uma dimensão argumentativa, entende-se que todo e qualquer discurso é passível de análise argumentativa. Contudo, como explicitado por Fiorin (2015), os trabalhos acerca desse elemento básico do discurso não são abundantes. E, até onde se viu, os estudos argumentativos que se valem especificamente do discurso oral - no que tange à esfera nacional - são escassos. À vista disso, este estudo se propõe a preencher essa lacuna nos estudos argumentativos e, sobretudo, nos estudos argumentativos da fala.

Para tanto, o material analítico deste trabalho compreende interações naturalísticas de fala pertencentes ao gênero discursivo interrogatório policial. Objetiva-se, assim, analisar fragmentos de fala pertencentes ao gênero supracitado, de modo a investigar (1) se o ethos prévio (AMOSSY, 2005) ou pré-discursivo (MAINGUENEAU, 2008) dos participantes do interrogatório policial se confirma no ethos discursivo dos enunciadores; e (2) os tipos de argumentos (FIORIN, 2015) utilizados pelos enunciadores do interrogatório policial.

A seguir, apresenta-se o aporte teórico que serve de alicerce para o entendimento dos conceitos referentes ao ethos e aos tipos de argumentos. Posteriormente, é apresentada a análise de três fragmentos de fala de interrogatórios policiais, seguida das considerações finais deste artigo.

\section{Aporte Teórico}

Os fundamentos teóricos que embasam este capítulo dividem-se em duas seções: a primeira delas abarca o ethos e os seus principais conceitos e características; a segunda, por sua vez, contempla os tipos de argumentos identificados na análise de dados deste estudo, que será apresentada posteriormente.

\subsection{Ethos: a construção da imagem de si}

Uma das noções prototípicas de ethos relaciona-se à representação de si mesmo que um locutor ativa em seus interlocutores ao tomar a palavra (MAINGUENEAU, 2008). Os conceitos relacionados ao ethos, todavia, perpassam diferentes épocas e autores. Em razão disso, Maingueneau (2008, p. 12,) explicita que se a intenção é, de fato, explorá-los, "somos obrigados a inscrevê-la [a noção de ethos] numa problemática precisa, privilegiando esta ou aquela faceta, em função [...] do corpus que nos propomos a analisar e dos objetivos da pesquisa [...]".

Diante disso, este estudo leva em consideração uma noção mais contemporânea do ethos (AMOSSY, 2005), que combina a sociologia e a pragmática. Isso porque "não se pode separar o ethos discursivo da posição institucional do locutor, nem dissociar totalmente a interlocução da interação social como troca simbólica" (AMOSSY, 2005, p. 136). Em outras palavras, entende-se que o ethos não deve ser levado em conta apenas de maneira exterior (ethos institucional) ou apenas de modo interno (ethos discursivo). É na complementaridade dessas duas concepções que este estudo focaliza a análise. 
No que concerne ao ethos institucional, Amossy (2005) explica que a posição institucional de um orador, assim como o grau de legitimidade por ele conferido, são capazes de contribuir para o ocasionamento de uma imagem prévia. Trata-se do ethos prévio do orador ou, como denominado por Maingueneau (2008), do ethos pré-discursivo. Tendo em vista os participantes principais do interrogatório policial ${ }^{3}$, a eles também é conferida uma imagem prévia.

Em relação ao ethos prévio de um policial civil, por exemplo, em termos de senso comum, a ele é conferida a imagem de investigador, responsável pela segurança pública e, portanto, pelo bemestar social (GUIA DA CARREIRA, 2017). Assim, enxerga-se nele a imagem de um cumpridor das leis nacionais, estaduais e municipais no dia a dia de sua profissão. Ademais, o policial investigador possui autoridade em relação aos cidadãos comuns, sobretudo aos interrogados acusados por crimes. No que se refere ao ethos prévio de um interrogado acusado por algum crime ${ }^{4}$, tendo em vista a opinião pública por meio de comentários de notícias na internet, pode-se observar que a ele é conferida uma imagem de: criminoso, violento e bandido (G1 RS, 2015; 2016). À vista disso, concebe-se a ele a representação de alguém inferior, que se encontra em uma situação de suscetibilidade em relação ao policial investigador.

No que tange ao ethos discursivo, esse conceito remete à imagem de si que é construída ao longo do discurso e que é "constitutiva da interação verbal" (AMOSSY, 2005, p. 137), determinando, em larga parte, o agir do locutor sobre seus alocutários. Esse ethos discursivo é constituído de elementos capazes de confirmar, reelaborar ou transformar a imagem prévia que um auditório possui sobre o locutor (ethos prévio). Verifica-se, assim a importância da articulação entre a pragmática e a reflexão sociológica na construção de um ethos, uma vez que é em uma espécie de continum entre a autoridade institucional, o imaginário social e a construção discursiva que o ethos é estabelecido (AMOSSY, 2005).

\subsection{Os Tipos de Argumentos}

Bakthin (1992, p. 345) explica que o enunciado se constitui "[...] um elo na cadeia da comunicação verbal de uma dada esfera" e cujas fronteiras "[...] determinam-se pela alternância dos sujeitos falantes". O enunciado, portanto, não é autossuficiente. Ele é responsivo a enunciados anteriores dentro de determinado contexto (BAKTHIN, 1992).

É nessa perspectiva de modo de funcionamento dialógico do discurso que Fiorin (2015) se ampara ao afirmar que todos os discursos possuem uma dimensão argumentativa:

\section{$\mathrm{Na}$ medida em que um discurso é sempre um discurso sobre outro discurso, todos os discursos são argumentativos, pois todos eles fazem parte de uma controvérsia, refutando, apoiando, contestando, sustentando, contradizendo um dado posicionamento (FIORIN, 2015, p. 29).}

Com base nessa dimensão discursiva dialógica e considerando os estudos de Perelman \& Olbrecths-Tyteca (2014), Fiorin (2015) apresenta os clássicos tipos de argumentos. Apesar de este estudo reconhecer a importância de todos eles, optou-se por discorrer apenas sobre aqueles contemplados a posteriori no capítulo de análise: argumento de comparação, argumentum ad hominem, argumentum ad verecundiam, argumentum ad misericordiam, argumentum ad baculum, e o recurso ao ethos do enunciador.

\footnotetext{
${ }^{3}$ No Brasil, os principais participantes do interrogatório policial consistem em um (ou mais) policial civil (geralmente o Delegado de Polícia) e um interrogado acusado por algum crime. Contudo, também podem participar do interrogatório policial: um advogado de defesa do interrogado; e um responsável legal pelo acusado no caso deste possuir menos que dezoito anos.

$4 \mathrm{Na}$ identificação do ethos prévio do interrogado, optou-se por descrevê-lo de maneira geral, sem levar em conta as especificidades dos tipos de crimes. Isso porque o corpus deste estudo se vale de crimes de diferentes proporções.
} 


\subsubsection{Argumento de Comparação}

O argumento de comparação consiste em um argumento quase lógico ${ }^{5}$ fundado no princípio da identidade. Trata-se de quando o enunciador não expõe as características ou as funções de determinado objeto, entretanto, escolhe outro objeto mais conhecido e realiza aproximações entre eles (FIORIN, 2015).

\subsubsection{Argumentum Ad Hominem}

$\mathrm{O}$ argumentum ad hominem ou, em outras palavras, o argumento dirigido à pessoa, consiste em um argumento de coexistência, pois "[...] relaciona um atributo com a essência [...] ou um ato com a pessoa" (FIORIN, 2015, p. 170). Trata-se de um argumento fundamentado na estrutura da realidade. Esse argumento dirigido à pessoa desqualifica o oponente e o apresenta como alguém inconsequente, não confiável ou incompetente. Faz-se importante salientar que esse tipo de argumento se dirige à audiência e não ao oponente. Confronta-se, assim, a pessoa com seus discursos ou seus atos (FIORIN, 2015).

\subsubsection{Argumentum Ad Verecundiam}

$\mathrm{O}$ argumentum ad verecundiam ou, dito de outra forma, o argumento de autoridade, assim como o argumentum ad hominem, consiste em um argumento de coexistência, fundamentado na estrutura da realidade, isto é, baseia-se nas "[...] relações que o nosso sistema de significação considera existentes no mundo objetivo [...]" (FIORIN, 2015, p. 149). O argumento de autoridade "supõe um respeito, uma reverência em relação à autoridade invocada, porque ela é especialmente confiável e reconhecida como fonte de conhecimento num dado tema" (FIORIN, 2015, p. 176). Fiorin (2015) ainda explicita que se pode recorrer a dois tipos de autoridade: (1) a do domínio do saber; e (2) a da ordem do poder. A primeira condiz ao conhecimento que um perito ou um especialista possui; a segunda, por sua vez, remete ao sujeito que exerce comando sobre os demais.

\subsubsection{Argumentum Ad Misericordiam}

O argumentum ad misericordiam se trata daquele que apela para a piedade, isto é, aquele que revela um sujeito como digno de pena. Explora-se nele o sentimento de culpa, assim como a simpatia por uma dada causa ou por alguém (FIORIN, 2015). Fiorin (2015) ainda explica que esse tipo de argumento é recorrente no Direito Penal. O argumentum ad misericordiam não se baseia no fato que se encontra em pauta, em vez disso, ampara-se em intenções, em outras situações: no lugar da discussão da tese que deveria ser debatida, apela-se para o sentimentalismo, para a sensibilidade. (FIORIN, 2015).

\subsubsection{Argumentum Ad Baculum}

O Argumentum ad baculum consiste em um argumento que apela para a força e que se direciona para o futuro, uma vez que "[...] o enunciador força o enunciatário a aceitar sua proposta, recorrendo a uma ameaça a uma proibição, a um valor negativo" (FIORIN, 2015, p. 227). Um exemplo prototípico desse tipo de argumento diz respeito às Leis e a todas as suas punições (FIORIN, 2015).

\subsubsection{O Recurso ao Ethos do enunciador}

\footnotetext{
5 Argumentos quase lógicos são aqueles que lembram os raciocínios formais, dedutivos, no entanto, pelo fato de empregarem a linguagem natural, isto é, ordinária, são passíveis de interpretações variadas.
} 
Por fim, discorre-se sobre o recurso ao ethos do enunciador. Apesar de não consistir um "tipo de argumento" assim como os discriminados nas subseções anteriores, trata-se de um recurso do qual todos os tipos de argumentos podem se valer. Partindo do pressuposto de que o ethos corresponde "[...] a uma imagem que se constrói no próprio ato de dizer" (FIORIN, 2015, p. 228), a comunicação não decorre do real autor de determinado ato de fala, mas da imagem de si mesmo por ele construída ao falar. Essa imagem encontra-se na materialidade discursiva de uma totalidade, nas marcas composicionais do discurso do enunciador (FIORIN, 2015).

Ao fazer menção a Aristóteles, Fiorin (2015) explica que se costuma acreditar mais em um sujeito honesto do que desonesto, em um sujeito sensato do que em um sujeito não criterioso, em um sujeito franco do que em um sujeito que parece escorregadio. Em outras palavras, costuma-se crer "mais" naqueles que transmitem uma imagem de ponderação, de coragem e de honestidade — imagens essas, que são construídas ao longo da fala e/ou da escrita.

\section{Análise: Os Tipos de Argumentos na Construção do Ethos}

Antes de adentrar a análise propriamente dita, faz-se necessário discorrer a respeito do corpus que compreende este estudo.

Como mencionado na introdução, este trabalho focaliza a análise em um gênero discursivo oral: o interrogatório policial. Escolheu-se utilizar, como material analítico, três fragmentos de fala de interrogatórios policiais gravados em áudio e vídeo entre junho de 2017 e janeiro de 2018. Tratase de interrogatórios policiais gravados em uma Delegacia de Polícia Civil do Estado do Rio Grande do Sul, Brasil.

Para representar as interações gravadas da maneira mais fiel às reais possível, optou-se por utilizar, na transcrição dos interrogatórios, as convenções propostas por Jefferson (1984), adaptadas pelo Grupo de Pesquisa Fala-em-Interação em Contextos Institucionais e Não Institucionais, com marcações sugeridas pelo GAT2 (SELTING et al., 2011) ${ }^{6}$ :

FIGURA 1 - CONVENÇÕES DE TRANSCRIÇÃO

\begin{tabular}{|l|l|}
\hline$(1.8)$ & Pausa \\
\hline$()$. & Micropausa \\
\hline$=$ & Fala colada \\
\hline$[$ Texto $]$ & Falas sobrepostas \\
\hline, & Entonação contínua \\
\hline$\uparrow$ texto & Entonação ascendente da sílaba \\
\hline$\downarrow$ texto & Entonação descendente da sílaba \\
\hline$\cdot$ & Entonação descendente da UCT \\
\hline$?$ & Entonação ascendente da UCT \\
\hline- & Marca de interrupção abrupta da fala \\
\hline$:::$ & Alongamento de som \\
\hline$>$ Texto $<$ & Fala acelerada \\
\hline$>>$ Texto $<<$ & Fala muito acelerada \\
\hline$<$ Texto $>$ & Fala mais lenta \\
\hline$<<$ Texto $>>$ & Fala muito mais lenta \\
\hline TEXTO & Fala com volume mais alto \\
\hline${ }^{\circ}$ texto $^{\circ}$ & Volume baixo \\
\hline${ }^{\circ 0}$ texto $^{\circ 0}$ & Volume muito baixo \\
\hline
\end{tabular}

"GAT é o acrônimo de "Gesprächsanalytisches Transkriptionssystem" (Sistema de Transcrição de Análise da Conversa e do Discurso).

7 UCT: Unidade de Construção de Turno. 


\begin{tabular}{|l|l|}
\hline Texto & Sílaba, palavra ou som acentuado \\
\hline (Texto) & Dúvidas do/a transcritor/a \\
\hline Xxxx & Fala inaudível \\
\hline$(($ Texto $))$ & Comentários da transcritora \\
\hline bhbh & Riso aspirado \\
\hline hahabehehibi & Risada com som de vogal \\
\hline$\{\{$ rindo $\}$ texto $\}$ & Turnos ou palavras pronunciadas rindo \\
\hline .hhh & Inspiração audível \\
\hline
\end{tabular}

Fonte: Traduzidas e adaptadas de Jefferson (1984).

Destaca-se que os elementos que compõem um gênero discursivo oral, como o interrogatório policial, não dizem respeito apenas à fala em si, mas também a suspiros, pausas, sobreposições de fala, dentre outros. Assim, é possível afirmar que a transcrição se trata de uma ferramenta que permite que outras pessoas que não possuem acesso às interações gravadas possam acessá-las da maneira mais "real" possível.

Faz-se importante esclarecer que, nas transcrições, optou-se por utilizar as iniciais POL e INT para identificar o policial e o interrogado, respectivamente. Além do mais, apesar do nome dos participantes aparecer no momento da contextualização das interações e, por vezes, na análise, trata-se de pseudônimos.

\subsection{Fragmento I}

O primeiro excerto de fala a integrar a análise compreende um interrogatório policial cujos participantes são: Mário, o policial (POL); Frederico, interrogado acusado de uma tentativa de homicídio (INT); e Lucas, advogado de defesa do interrogado. No fragmento escolhido para análise não há a interação verbal do advogado.

Conforme apontam as investigações, o interrogado teria esfaqueado um homem. Já no início do interrogatório, o acusado acaba confessando o crime, alegando ter agido em legítima defesa. Isso porque, de acordo com sua versão dos fatos, a esposa da vítima, que reside próximo ao seu local de trabalho ${ }^{8}$, passou na rua oferecendo-lhe um biscoito caseiro. Após o interrogado ter aceitado e comido o biscoito, o esposo da mulher, enciumado, teria lhe agredido com um soco, ameaçando-o com espetos. A vítima ainda teria ameaçado matar o interrogado. O excerto a seguir acontece um pouco antes da metade do interrogatório.

\footnotetext{
${ }^{8}$ Frederico trabalha em uma fruteira.
} 
FIGURA 2 - FRAGMENTO I: DP_MÁRIO_LUCAS_FREDERICO_18_01_2018

\begin{tabular}{lll}
\hline 01 POL: & e aí? \\
02 & $(0.7)$ \\
03 INT: & aí ele: : >le ele< ele foi levantô: de no:vo \\
04 & oali na hora que ele levantô eu dei uma: : uma \\
05 & facada nele eu dei uma facada nele com a- \\
06 & com a: mão esque:rda, .h m: pegô mais ou \\
07 & menos sei lá na: : nessa parte aqui do tórax \\
08 & tipo assim \\
09 & (.) \\
10 POL: & [mhm] \\
11 INT: & facada (0.6) eu poderia tê executado ele \\
12 & poderia tê matado mas eu achei uma covardia \\
13 & eu: $\mathrm{n}: a ̃ o$ tenho: h é antecedente nada po- por- \\
14 & por crime assim de: de matá pessoas (.) até: \\
15 & (.) o que eu fiz foi pra me defendê porque \\
16 & eu nunca matei ninguém, \\
17 & (2.0) \\
18 & e ele continuô gritando que ia me matá \\
19 INT: &
\end{tabular}

Fonte: Elaborado pelas autoras com base nos registros de áudio e vídeo.

No fragmento acima, observa-se que há pouca participação do policial. Como se pode ver, ele não faz o uso de nenhum tipo de argumento, entretanto, acaba por confirmar, de certa forma, seu ethos prévio de "investigador", uma vez que busca por informações acerca do crime: "e aî?" (linha 01). Chama-se a atenção, também, para o continuador "mhm" por ele fornecido na linha 10. Trata-se de uma maneira de ele mostrar orientação ao seu interlocutor.

Observa-se que o interrogado, ao longo das linhas 11-17, utiliza-se do argumentum ad misericordiam, isto é, do argumento que apela para a piedade, de forma a confirmar que teria agido em legítima defesa amparando-se em outras intenções, que não a de matar a vítima: "eu poderia tê dado mais facada / eu poderia tê executado ele poderia tê matado mas eu achei uma covardia eu:: n:ão tenho: .h é antecedente nada po- por- por crime assim de: matá pessoas (.) até (.) o que eu fiz foi pra me defendê porque eu nunca matei ninguém". Ao avaliar como "covardia" o crime de homicídio e, em seguida, alegar não possuir antecedentes criminais por esse tipo de crime e ter agido em legítima defesa, o interrogado apela para o sentimentalismo, revelando-se um sujeito digno de pena. Chama-se a atenção para o advérbio de negação "nunca" — proferido com ênfase - que compõe o final do turno de fala do interrogado. Trata-se de uma maneira de o interrogado revelar uma identidade pacificadora e de inculpabilidade, capaz de legitimar a sua justificativa de ter agido em legítima defesa. O ethos construído pelo interrogado ao longo de seu discurso é de uma pessoa de boa índole e digna de compaixão por não cometer homicídios. Assim, em seu discurso, o interrogado reelabora a imagem prévia que se tem de uma pessoa acusada por algum crime (uma pessoa criminosa, violenta).

Não se pode deixar de considerar o último turno de fala do interrogado na linha 19: "e ele continuô gritando que ia me matá". Observa-se que, utilizando-se do argumentum ad misericordiam, o interrogado argumenta sem se basear no fato que se encontra em pauta (o crime de tentativa de 
homicídio pelo qual está sendo acusado), apoiando-se em uma outra situação: a de a vítima tê-lo ameaçado de morte. De novo, o uso desse tipo de argumento corrobora para a construção de um ethos que revela merecimento de compaixão.

\subsection{Fragmento II}

O próximo fragmento de fala a compor este estudo contempla um interrogatório policial que contou com a participação do policial Manuel (POL), de um interrogado acusado de roubo de uma motocicleta, Santiago (INT), e da mãe do interrogado, Janete. A presença da mãe do interrogado se deu em razão de Santiago ser menor de dezoito anos ${ }^{9}$. No excerto apresentado a seguir, entretanto, não se tem a interação verbal de Janete. $O$ fragmento abaixo acontece no início do interrogatório.

\section{FIGURA 3 - FRAGMENTO II: DP_MANUEL_JANETE_SANTIAGO_01_06_2017}

\begin{tabular}{|c|c|}
\hline $\begin{array}{l}01 \text { POL: } \\
02\end{array}$ & $\begin{array}{l}\text { [a ví]tima te reconheceu tu sabia } \\
(0.5)\end{array}$ \\
\hline 03 POL: & que a vítima da- o proprietário da:- moto é um \\
\hline 04 & policial militar tu sabia diłsso \\
\hline 05 & $(2.9)$ \\
\hline 06 INT: & $\mathrm{ma}[\mathrm{s}$ eu-] \\
\hline 07 POL: & [sabia] disso? \\
\hline 08 & $(0.6)$ \\
\hline 09 INT : & não sabia de nada não tô sabendo de nada \\
\hline 10 & $()$. \\
\hline 11 POL: & tá bom \\
\hline 12 & $(1.4)$ \\
\hline 13 INT: & desde quando eu tomei um tiro eu comecei a \\
\hline 14 & trabalhá e: : não aprontei mais nada \\
\hline 15 & $(0.5)$ \\
\hline 16 POL: & o: : lha que as informação não são e:ssa \\
\hline 17 & $(7.9)$ \\
\hline
\end{tabular}

Fonte: Elaborada pelas autoras com base nos registros de áudio e vídeo.

Ao longo das linhas 01-07, observa-se que o policial realiza três perguntas em sequência ao interrogado, sendo que a última acontece em sobreposição à fala do acusado: "a vítima te reconheceu tu sabia / que a vítima da- o proprietário da:- moto é um policial militar tu sabia di $\uparrow s s o$ / [sabia] disso?" ${ }^{10}$. Pode-se observar, pelo modo como realiza essas perguntas (repetição, entonação ascendente ao final das duas últimas perguntas), e também por sua composição, que o policial faz jus ao seu ethos de investigador/inquiridor. Além disso, ao proferir "a vítima te reconheceu tu sabia", ele atribui à vítima uma autoridade do domínio do saber e, dessa forma, atribui a si mesmo uma autoridade desse mesmo domínio, uma vez que possui o conhecimento de que a vítima

\footnotetext{
${ }_{9}^{9}$ No momento do interrogatório, Santiago tinha 17 anos.

${ }^{10}$ Entende-se que essas perguntas em sequência decorrem da ausência de resposta do interrogado, como se pode visualizar pelas pausas de meio segundo e de quase três segundos nas linhas 02 e 05 , respectivamente.
} 
reconhecera o acusado. Ao proferir "o proprietário da:- moto é um policial militar tu sabia di $\uparrow s s o "$, o policial atribui ao proprietário do item roubado a autoridade do poder, tendo em vista a profissão "policial militar", e atribui a si mesmo a autoridade epistêmica, uma vez que tem conhecimento disso. Ao realizar essas perguntas, o policial confirma seu ethos prévio de investigador, uma vez que revela desafiar o interrogado de modo a buscar informações acerca do crime sob investigação.

O interrogado, depois de prover uma resposta às perguntas do policial ("não sabia de nada não tô sabendo de nada"), justifica-se por se revelar sem acesso epistêmico em relação à vítima e ao crime: "desde quando eu tomei um tiro eu comecei a trabalhá e:: não aprontei mais nada" (linhas 13-14). Pode-se observar que, em sua justificativa, o interrogado se utiliza do argumentum ad misericordiam, pois se ampara em uma outra situação: no lugar da discussão da tese que deveria ser debatida (o roubo da motocicleta; a informação de que a vítima o reconhecera; o conhecimento de que o proprietário do item roubado é um policial militar), o acusado apela para a sensibilidade ("quando tomei um tiro"; "comecei a trabalhá"; "não aprontei mais nada") de forma a revelar-se como inimputável pelo crime. Em seu discurso, o acusado constrói a imagem de uma pessoa trabalhadora, de bom caráter e que, apesar de ter "aprontado" no passado, não o faz mais no presente. Dessa forma, revela não poder ser acusado por um crime "no presente". Como no fragmento I, observa-se que o interrogado constrói uma imagem que não condiz ao ethos prévio de uma pessoa acusada por algum crime.

$\mathrm{Na}$ linha 16, o policial, ao proferir "o:::lha que as informação não são e:ssa", confronta o acusado com seu discurso e seus atos, característica essa do argumentum ad hominem. Além disso, pode-se dizer que o investigador também invoca uma autoridade da ordem do saber, revelando que as informações fornecidas pelo interrogado não condizem com as informações que o policial possui. Dessa forma, o policial também parece fazer o uso do argumentum ad verecundiam (argumento de autoridade), que corrobora com a imagem prévia - de autoridade em relação ao acusado - de um policial civil.

\subsection{Fragmento III}

O último fragmento a integrar a análise deste estudo contempla um interrogatório policial cujos participantes são dois: o policial Pablo (POL), e uma interrogada acusada de agressão física (INT), Amanda. De acordo com as investigações, Amanda, junto de seu companheiro, teria agredido fisicamente dois jovens em sua residência. Segundo a própria interrogada, essa agressão física é resultado de um episódio que acontecera anteriormente: esses dois jovens teriam assaltado a filha da acusada e uma colega da garota (ambas com cerca de 12-13 anos), apontando-lhes uma arma e tomando-lhes os telefones celulares. A polícia teve conhecimento dessa agressão porque o episódio fora gravado em vídeo pelo companheiro de Amanda e divulgado por meio de um aplicativo de celular. O excerto a seguir acontece no início do interrogatório:

FIGURA 4 - FRAGMENTO III: DP_PABLO_AMANDA_01_06_2017 


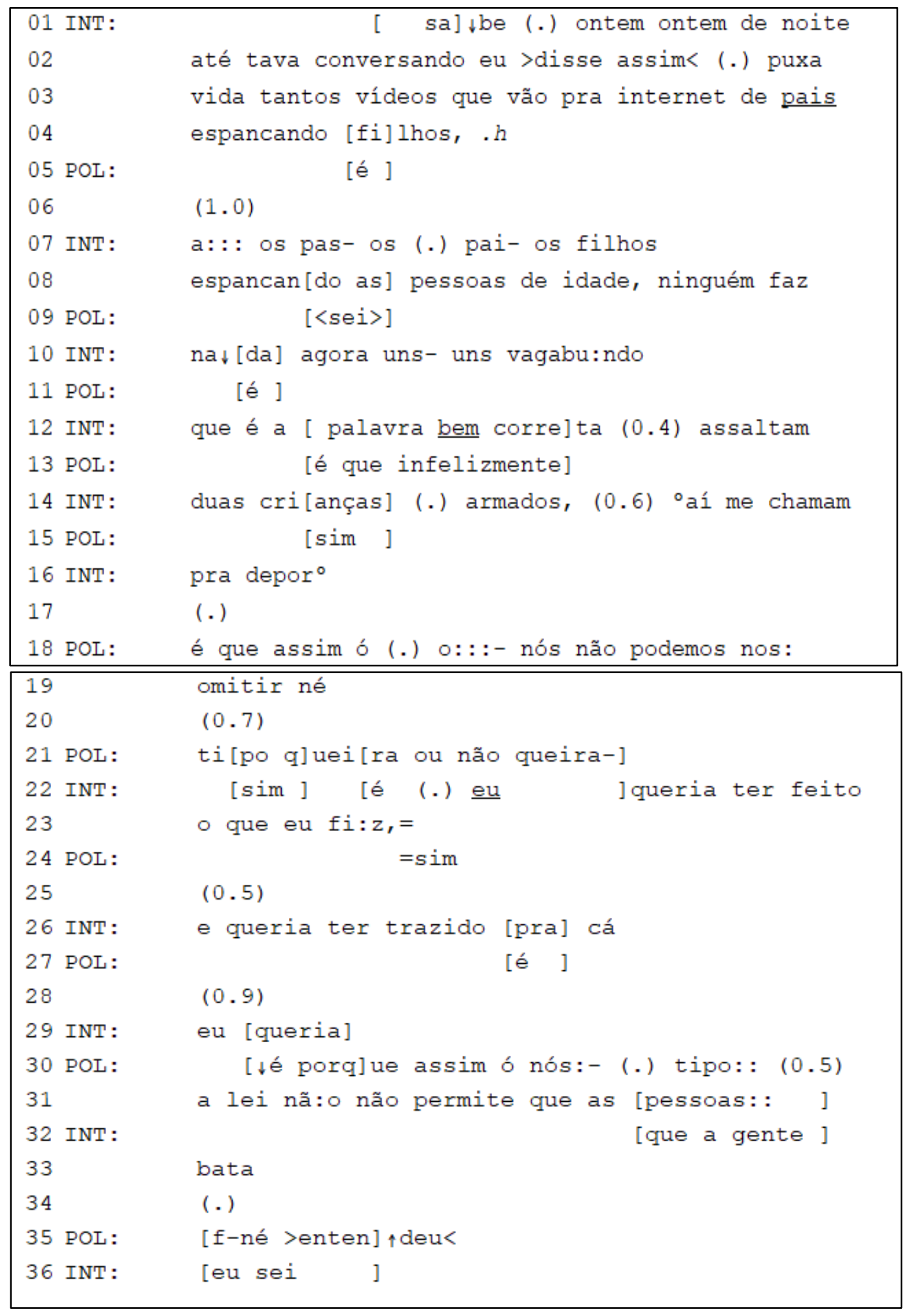

Fonte: Elaborada pelas autoras com base nos registros de áudio e vídeo.

Ao longo das linhas 03-04, 07-10 e 12-16, a interrogada utiliza-se do argumento de comparação ao comparar o ato de agressão física cometido por ela com outros atos de violência cometidos por outras pessoas e, principalmente, contra outras pessoas: "tantos vídeos que vão pra internet de pais espancando [fi]lhos, $. h /$ a::: os pas- os (.) pai- os filhos espancan[do as] pessoas de idade, ninguém faz na $\downarrow[\mathrm{da}]$ agora uns- uns vagabu:ndo que é a [palavra bem corre]ta / assaltam 
duas cri[anças] (.) armados, / 'aí me chamam pra depor "”. Pode-se observar, que ao fazer menção aos garotos que roubaram os celulares de sua filha e de uma colega dela, a interrogada utiliza-se, também, do argumentum ad hominem, uma vez que desqualifica os oponentes (nesse caso, os garotos - que são as vítimas). Além disso, como explicado por Fiorin (2015), esse tipo de argumento se dirige à audiência (no caso, ao policial) e não aos oponentes. A imagem construída ao longo do discurso da interrogada é a de indignação por estar respondendo a um crime. Mais uma vez, observa-se que se trata de uma imagem distinta àquela do ethos prévio de uma pessoa acusada por algum tipo de crime.

O policial, apesar de mostrar-se, de certa forma, alinhado à interrogada, como se pode observar nas linhas 05, 09, 11 e 15 ("é / <sei> / é / sim"), utiliza-se do argumento ad baculum ao revelar-se orientado à força da Lei: "é que assim ó / nós não podemos nos: omitir né / a lei nã:o permite que as [pessoas::]”. Essa atenção à Lei é capaz de confirmar o ethos prévio de um policial: o de respeito às Leis, sejam elas federais, estaduais ou municipais.

\section{CONSIDERAÇÕES FINAIS}

Este estudo se propôs a investigar, em fragmentos de fala constituintes do gênero discursivo interrogatório policial, (1) se o ethos prévio dos participantes do interrogatório se confirma no ethos discursivo dos enunciadores; e (2) os tipos de argumentos utilizados pelos enunciadores no evento interacional em pauta.

Por meio da análise, alicerçada nos pressupostos teóricos de AMOSSY (2005) e FIORIN (2015), foi possível perceber que os tipos de argumentos utilizados pelos policiais e pelos interrogados nas interações operaram como recursos para a construção do ethos discursivo dos enunciadores. Quanto ao primeiro propósito desse estudo, verificou-se que no que tange aos policiais, seu ethos prévio (imagem prévia de investigadores, respeitadores da Lei, etc.) se confirmou discursivamente em todos os fragmentos de fala analisados. Em relação aos interrogados, a imagem prévia de "criminosos", "violentos", etc., foi reelaborada pelos enunciadores no discurso para uma imagem de pessoas "de caráter", "de boa índole", "dignas de compaixão" e, no caso específico do último fragmento de fala, o ethos discursivo da interrogada revelou uma pessoa totalmente insatisfeita por estar sendo interrogada. Todas essas imagens construídas discursivamente mostraram-se consequência dos tipos de argumentos utilizados pelos enunciadores. No caso dos interrogados, essas imagens todas mostraram-se operar em favor da construção de uma identidade pacificadora e de inculpabilidade pela imputação que lhes fora atribuída.

Quanto ao segundo propósito deste estudo, identificou-se uma série de tipos de argumentos utilizados pelos enunciadores do gênero discursivo interrogatório policial, a saber: argumento de comparação, argumentum ad hominem, argumentum ad verecundiam, argumentum ad misericordiam, argumentum ad baculum. O argumentum ad misericordiam, isto é, aquele que apela para a piedade, predominou nas análises dos fragmentos analisados neste estudo. E esse achado corrobora com o que foi exposto por Fiorin (2015): que esse tipo de argumento é corrente na justiça penal.

Finda-se reconhecendo a relevância dos tipos de argumentos como recursos significativos para a construção do ethos discursivo dos enunciadores.

\section{REFERÊNCIAS BIBLIOGRÁFICAS}

AMOSSY, R. O Ethos na intersecção das disciplinas: retórica, pragmática, sociologia dos campos. In: AMOSSY, Ruth. (Org.) Imagens de si no discurso: a construção do ethos. São Paulo: Contexto, 2005. p. 119-136.

BAKHTIN, M. Estética da criação verbal. São Paulo: Martins Fontes, 1992. 
FIORIN, J. L. Argumentação. Editora Contexto, 2015, 272 p.

GUIA DA CARREIRA. Polícia Civil: profissão e mercado de trabalho. 2017. Disponível em <https://www.guiadacarreira.com.br/carreira/policia-civil> Acesso em: 23 Jul. 2018.

G1 RIO GRANDE DO SUL. Madrasta de Bernardo e amiga terão de participar de audiência, diz justiça. 2015. Disponível em: <http://g1.globo.com/rs/rio-grande-dosul/noticia/2015/05/madrasta-de-bernardo-e-amiga-terao-de-participar-de-audiencia-dizjustica.html> Acesso em 23 Jul. 2018.

G1 RIO GRANDE DO SUL. Três suspeitos de matar mulher em frente à filha são interrogados no RS. 2016. Disponível em: <http://g1.globo.com/rs/rio-grande-dosul/noticia/2016/12/tres-suspeitos-de-matar-mulher-em-frente-filha-sao-interrogados-nors.html> Acesso em: 23 Jul. 2018.

JEFFERSON, G. Transcript notation. In: ATKINSON, J. M.; HERITAGE, J. Structures of Social Action: studies in conversation analysis. New York: Cambridge University Press, 1984. p. ix-xvi.

MAINGUENEAU, D. A propósito do ethos. In: MOTTA, Ana. Raquel; SALGADO, Luciana. (Orgs.) Ethos discursivo. São Paulo: Contexto, 2008. p. 11-29.

PERELMAN, C.; OLBRECHTS-TYTECA. Tratado da argumentação: a Nova Retórica. São Paulo: Martins Fontes, 2014.

SELTING, M.; et al. A system for transcribing talk-in-interaction: GAT2 translated and adapted for English by Elizabeth Couper-Kuhlen and Dagmar Barth-Weingarten. Gesprächsforschung - Online-Zeitschrift zur verbalen Interaktion, p. 1-51, 2011. 